\title{
ANTHROPOMETRIC AND CARDIOVASCULAR CHARACTERISTICS OF YOUNG ELITE MALE HANDBALL PLAYERS ACCORDING TO PLAYING POSITIONS
}

\author{
Alexandra Cselkó \\ University of Pecs, Doctoral School of Health Sciences, Pecs, Hungary \\ University of Pecs, Department of Leisure Sports and Recreation, Pecs, Hungary \\ Zita László \\ University of Pecs, Department of Individual Sports, Pecs, Hungary \\ Éva Tékus \\ University of Pecs, Doctoral School of Health Sciences, Pecs, Hungary \\ University of Pecs, Department of Sportbiology, Pecs, Hungary \\ Márta Wilhelm* \\ University of Pecs, Department of Leisure Sports and Recreation, Pecs, Hungary
}

\section{Abstract}

The purpose of the present study was to examine the anthropometric parameters and cardiopulmonary functions of young handball players in different playing positions. 15 male handball players from first division (mean age: $16.06 \pm 0.63 \mathrm{yrs}$ ) participated in our research who were divided by their playing positions. First anthropometric parameters, body composition and pulmonary functions in rest were measured. Then physiological changes of the players were tested with Bruce protocol. We found that wings differed the most in morphological characteristics from other players. We did not find significant differences in pulmonary functions among positions. The highest values of Tidal volume in the vita maxima test were found in pivots $(2.82 \pm 0.151)$ which is significantly higher than Tidal volume of goalkeepers $(\mathrm{p}=0.006)$. The highest mean value of maximal oxygen uptake was recorded $(73.93 \pm 9.41 \mathrm{ml} / \mathrm{kg} / \mathrm{min})$ in wings. Altogether in our study important differences were seen in physique and in performance also among young handball players.

Keywords: handball, anthropometry, endurance, pulmonary function, Bruce protocol

\footnotetext{
* Corresponding author. University of Pecs, Department of Leisure Sports and Recreation, Ifjusag Street 6, 7624 Pecs, Hungary, e-mail: mwilhelm@gamma.ttk.pte.hu

(C) 2013 Faculty of Sport and Physical Education, University of Novi Sad, Serbia
} 


\section{Introduction}

Handball is one of the most popular team sports in European countries. In the last years the game became faster therefore athletic skills are even more important for players. Short maximal intensity movements and medium intensity actions for longer time alternately and repetitively appear in this sport game. The intermittent actions, changes of offense and defense are large-scale exercises for players thus complex physical conditions are needed.

Players must have sport specific endurance for success, therefore cardiorespiratory functions of handball players were intensively studied (Buccheit et al., 2009; Loftin et al., 1996; Luszczyk et al., 2010; Vujkov, Đukic \& Drid, 2010). It has been shown earlier that some of the anthropometric parameters are essential factors for modern handball profile (stature, body mass, body fat percentage, specific girth, length and skinfold parameters) equally in young (Ibnziaten et al., 2002) and adult players (Hasan, Rahaman, Cable \& Reilly, 2007; Sibila, Vuleta \& Pori, 2004). There are significant differences in physical characteristics between playing positions (Massuca \& Fragoso, 2011; Srhoj, Marinovic \& Rogulj, 2002).

According to earlier research handball players must have well developed basic and specific motor abilities (conditional and coordination skills) paired with appropriate anthropometric parameters for highest efficiency on the court (Chaouachi et al., 2009; Galal El-Din, Zapartidis \& Ibrahim, 2011; Matthys et al., 2011; Mohamed et al., 2009; Sporis, Vuleta, D., Vuleta Jr., D. \& Milanović, 2010; Zapartidis, Vareltzis et al., 2009; Zapartidis, Toganidis et al., 2009; Ziv \& Lidor, 2009). Wings covered the greatest distance in match time and in specific running protocols (Cuesta, 1991; Sibila et al., 2004) on the field. Besides endurance accurate shots help to win the game which are also influenced by certain anthropometric parameters of the athletes (Gorostiaga et al., 2005; Marques, Tillaar, Vescovi \& González-Badillo, 2007; Rivilla-Garcia, Navarro, Grande, Ignatova \& Sampedro, 2010; Skoufas, Kotzamanidis, Hatzikotoylas, Bebetsos, \& Patikas, 2003; Zapartidis, Kororos, Christodoulidis, Skoufas \& Bayios, 2011).

One study measured longitudinal changes in anthropometric, physical parameters of young age groups: 13-17 years old handball players and found that coaches choose players for different positions by maturity and some anthropometrical parameters (Matthys, Vaeyens et al., 2013).

The aim of this study was (a) to measure the anthropometric characteristics of young male handball players; (b) to obtain data on physical performance of athletes with special attention to positions.

\section{Method}

\section{Participants}

Fifteen young male handball players participated in this study (mean age: $16.06 \pm 0.63 \mathrm{yrs,}$ Wings: $15.86 \pm 0.65$ yrs, Back court players: $16.03 \pm 0.66$ yrs, Pivots: $16.22 \pm 0.49$ yrs, Goalkeepers: $16.19 \pm 1.15 \mathrm{yrs})$. All athletes play in one of the first division handball clubs in Hungary. We divided the group of participants according to their playing positions: wings (W; $=3$ ), back court players $(\mathrm{B} ; \mathrm{n}=7)$, pivots $(\mathrm{P} ; \mathrm{n}=3)$ and goalkeepers $(\mathrm{GK} ; \mathrm{n}=2)$. Each subject underwent anthropometric measurements and a vita-maxima treadmill test. Participants wore proper clothing during all measurements. 
The study was approved by the Ethics Comette of the University and all subjects gave their consent to participate. Informed consent of University of Pecs, Institute of Sport Sciences and Physical Education was also given for this protocol.

\section{Anthropometric characteristics}

Twelve variables of girths (acromion, chest, biceps, forearm, wrist, hand, abdominal, buttocks, thigh, calf, knee and ankle) were measured with anthropometric tape-measure. Breadths of acromion, chest, humerus, femur and chest depth were tested with a sliding caliper. Data of arm and forearm lengths, iliocristale heights, sitting heights and seven skinfolds (biceps, triceps, subscapular, pectoralis, suprailiaca, thigh, calf) were also measured. Each parameter was assessed on the dominant side of subjects.

BMI was calculated as the ratio of body mass and the square of stature in meter $(\mathrm{kg} / \mathrm{m} 2)$. Bioimpedance analyzer (Omron BF300) was used to estimate body fat percentage and fat mass. Somatotypes of players were determined by Heath-Carter's modified method (Carter, Rose \& Duquest, 1983). Metric (MIX) and plastic (PLX) indexes were also calculated (Conrad, 1963).

\section{Pulmonary functions}

Pulmonary functions [forced vital capacity (FVC), FVC\%, forced expiratory volume in the $1^{\text {st }}$ second (FEV1), Tiffeneau-index (FEV1/FVC), peak expiratory flow (PEF), forced expiratory time (FET)] were tested with a spirometer (Spirodoc). Measurements were carried out twice and the better result was recorded.

\section{Treadmill test}

Bruce treadmill protocol was used to measure the cardiovascular and cardiorespiratory functions (Bruce, 1971). Each subject performed the exercise until exhaustion (vita maxima). At the start the speed of the treadmill was $2.74 \mathrm{~km} / \mathrm{h}$ (incline gradient $10 \%$ ). At three minutes intervals the speed and gradient were increased. A 12-lead electorcardiograph analyzed cardiac parameters. At the start of the protocol resting heart rate (RHR, bpm), later on maximal heart rate (HRmax) was also recorded. The gas analyzer (AT-60/Bruel gas analyser) collected data breath by breath during the test. Tidal volume (VT), maximal minute ventilation (VE), $\mathrm{O}_{2}$ consumption, relative maximal oxygen uptake (relVO 2 max), $\mathrm{CO}_{2}$ production, respiratory quotient (RQ) and metabolic rate $(\mathrm{MET})$ were continuously recorded. Oxygen pulse $\left(\mathrm{VO}_{2} / \mathrm{HR}\right)$ was monitored also.

\section{Statistical analysis}

One way ANOVA was applied for testing the significant differences of anthropometric parameters and cardiorespiratory functions between playing positions (Tukey post-hoc test). Normality and homogeneity was checked. Statistical significance was set at $p \leq 0.05$. 


\section{Results}

Anthropometric characteristics

The selected anthropometric characteristics and body composition of young male handball players are summarized in Table 1-2. Statistically significant differences were found between playing positions in lean body mass, biceps girth, buttock girth, thigh girth, ankle girth, chest breadth, forearm length, metric index and mesomorphic type. There were no significant differences in stature, body mass, body fat percentage and skinfolds based on the analysis of Tukey post-hoc test (Table 1).

Table 1

Anthropometric parameters of players and differences by playing positions

\begin{tabular}{|c|c|c|c|c|c|c|}
\hline & $W(n=3)$ & B $(n=7)$ & $\mathbf{P}(\mathbf{n}=3)$ & $\operatorname{GK}(n=2)$ & $\mathbf{F}$ & $\mathbf{P}$ \\
\hline Age (years) & $15.86 \pm 0.65$ & $16.03 \pm 0.66$ & $16.22 \pm 0.49$ & $16.19 \pm 1.15$ & 0.162 & 0.920 \\
\hline $\begin{array}{l}\text { Stature } \\
(\mathrm{cm})\end{array}$ & $175.67 \pm 10.02$ & $187.79 \pm 6.09$ & $184.00 \pm 3.61$ & $179.00 \pm 2.83$ & 2.835 & 0.087 \\
\hline $\begin{array}{l}\text { Body mass } \\
(\mathrm{kg})\end{array}$ & $61.43 \pm 5.05$ & $66.93 \pm 7.19$ & $80.50 \pm 7.54$ & $77.85 \pm 18.17$ & 3.371 & 0.058 \\
\hline $\begin{array}{l}\text { Body fat } \\
\%\end{array}$ & $11.90 \pm 0.85$ & $14.43 \pm 6.01$ & $19.67 \pm 1.44$ & $17.85 \pm 13.36$ & 1.006 & 0.426 \\
\hline $\begin{array}{l}\text { Lean body } \\
\text { mass (kg) }\end{array}$ & $54.10 \pm 4.28 *$ & $56.92 \pm 3.76$ & $64.77 \pm 5.27 *$ & $62.72 \pm 4.55$ & 4.230 & $0.032 *$ \\
\hline \multicolumn{7}{|c|}{ Girths } \\
\hline $\begin{array}{l}\text { Acromion } \\
(\mathrm{cm})\end{array}$ & $107.00 \pm 3.5$ & $107.71 \pm 3.64$ & $112.17 \pm 2.75$ & $112.00 \pm 7.07$ & 1.553 & 0.256 \\
\hline Chest $(\mathrm{cm})$ & $88.33 \pm 4.04$ & $86.71 \pm 4.34$ & $94.50 \pm 3.12$ & $94.75 \pm 10.25$ & 3.435 & 0.056 \\
\hline Biceps $(\mathrm{cm})$ & $25.83 \pm 0.76^{*}$ & $26.43 \pm 1.64 *$ & $30.17 \pm 1.60$ & $31.25 \pm 4.59 *$ & 5.476 & $0.015^{*}$ \\
\hline Forearm $(\mathrm{cm})$ & $26.00 \pm 1$ & $25.93 \pm 0.93$ & $28.33 \pm 1.26$ & $28.50 \pm 2.83$ & 4.000 & $0.038^{*}$ \\
\hline $\operatorname{Wrist}(\mathrm{cm})$ & $16.67 \pm 0.58$ & $16.96 \pm 0.83$ & $18.33 \pm 1.15$ & $17.50 \pm 0.70$ & 2.411 & 0.122 \\
\hline $\begin{array}{l}\text { Abdominal } \\
(\mathrm{cm})\end{array}$ & $74.33 \pm 2.08$ & $76.29 \pm 2.77$ & $85.00 \pm 5.00$ & $82.00 \pm 14.14$ & 2.859 & 0.086 \\
\hline Buttocks $(\mathrm{cm})$ & $91.33 \pm 2.87^{*}$ & $94.64 \pm 1.49$ & $101.83 \pm 1.76^{*}$ & $98.25 \pm 10.96$ & 4.463 & $0.028^{*}$ \\
\hline $\operatorname{Thigh}(\mathrm{cm})$ & $49.83 \pm 2.75 *$ & $50.93 \pm 3.18 *$ & $59.00 \pm 1.00 *$ & $57.00 \pm 7.07$ & 5.730 & $0.013^{*}$ \\
\hline $\operatorname{Calf}(\mathrm{cm})$ & $35.00 \pm 1.73$ & $35.43 \pm 4.25$ & $39.83 \pm 1.26$ & $40.25 \pm 3.89$ & 2.054 & 0.165 \\
\hline Ankle $(\mathrm{cm})$ & $23.93 \pm 0.11 *$ & $25.79 \pm 0.76$ & $27.33 \pm 0.76^{*}$ & $27.00 \pm 2.83 *$ & 5.890 & $0.012 *$ \\
\hline \multicolumn{7}{|c|}{ Breadths } \\
\hline $\operatorname{Acromion}(\mathrm{cm})$ & $41.50 \pm 1.32$ & $41.86 \pm 1.65$ & $44.50 \pm 3.00$ & $41.75 \pm 1.77$ & 1.648 & 0.235 \\
\hline \multicolumn{7}{|c|}{$\begin{array}{c}\text { Lengths } \\
\end{array}$} \\
\hline $\operatorname{Arm}(\mathrm{cm})$ & $91.50 \pm 20.37$ & $90.36 \pm 10.35$ & $82.67 \pm 2.52$ & $83.00 \pm 5.66$ & 0.510 & 0.684 \\
\hline $\operatorname{Forearm}(\mathrm{cm})$ & $45.33 \pm 0.58$ & $47.00 \pm 2.40 *$ & $42.33 \pm 2.52 *$ & $41.50 \pm 2.12 *$ & 5.196 & $0.018 *$ \\
\hline \multicolumn{7}{|c|}{$\begin{array}{c}\text { Somatotype } \\
\end{array}$} \\
\hline Endomorphy & $2.34 \pm 0.21$ & $2.87 \pm 0.65$ & $3.99 \pm 1.71$ & $4.39 \pm 1.89$ & 2.331 & 0.130 \\
\hline Mesomorphy & $3.35 \pm 1.74^{*}$ & $2.19 \pm 0.89^{*}$ & $4.67 \pm 1.27^{*}$ & $6.65 \pm 0.16^{*}$ & 9.283 & $0.002 * *$ \\
\hline Ectomorphy & $4.02 \pm 1.29$ & $5.34 \pm 1.16^{*}$ & $2.67 \pm 1.39^{*}$ & $2.33 \pm 1.86^{*}$ & 4.553 & $0.026^{*}$ \\
\hline Plastic index & $89.67 \pm 1.26$ & $89.54 \pm 2.64$ & $95.17 \pm 4.65$ & $92.00 \pm 6.36$ & 2.119 & 0.156 \\
\hline Metric index & $-0.20 \pm 0.60$ & $-1.12 \pm 0.59 *$ & $0.73 \pm 0.93 *$ & $-0.09 \pm 0.09$ & 5.689 & $0.015^{*}$ \\
\hline
\end{tabular}

Notes: W: Wing, B: Back court player, P: Pivot, GK: Goalkeeper * $\mathrm{p} \leq 0.05 ; * * \mathrm{p} \leq 0.01$ 
The tallest players are B $(187.79 \pm 6.09 \mathrm{~cm})$, and P have biggest weight $(80.50 \pm 7.54 \mathrm{~kg}) . \mathrm{W}$ players have the lowest body fat percentage $(11.90 \pm 0.85 \%)$ and generally the thinnest skinfolds (Table 2.). W and P significantly differed in most of the anthropometric parameters (Table 1). After the statistical analysis $P$ have more lean body mass $(p=0.044)$, greater buttocks girth $(p=0.026)$, thigh girth $(\mathrm{p}=0.031)$ and ankle girth $(\mathrm{p}=0.012)$ than $\mathrm{W}$.

Table 2

The lean body mass and selected skinfolds of young handball players

\begin{tabular}{|c|c|c|c|c|c|c|}
\hline & $\mathbf{W}(n=3)$ & $B(n=7)$ & $P(n=3)$ & $\operatorname{GK}(n=2)$ & $\mathbf{F}$ & $\mathbf{P}$ \\
\hline $\begin{array}{l}\text { Lean body mass } \\
(\mathrm{kg})\end{array}$ & $54.10 \pm 4.28 *$ & $56.92 \pm 3.76$ & $64.77 \pm 5.27 *$ & $62.72 \pm 4.55$ & 4.230 & $0.032 *$ \\
\hline \multicolumn{7}{|c|}{ Skinfolds } \\
\hline Biceps (mm) & $4.00 \pm 0.00$ & $3.71 \pm 0.95$ & $6.00 \pm 1.00$ & $7.00 \pm 4.24$ & 3.447 & 0.055 \\
\hline Triceps (mm) & $5.00 \pm 0.00$ & $7.43 \pm 2.69$ & $10.33 \pm 4.51$ & $11.00 \pm 7.07$ & 1.736 & 0.217 \\
\hline Subscapular (mm) & $7.33 \pm 1.53$ & $7.71 \pm 1.60$ & $11.00 \pm 8.66$ & $11.50 \pm 3.53$ & 0.880 & 0.481 \\
\hline Pectoral (mm) & $4.67 \pm 1.15$ & $5.29 \pm 2.36$ & $6.67 \pm 1.53$ & $9.5 \pm 4.95$ & 1.952 & 0.180 \\
\hline Suprailiac (mm) & $6.67 \pm 1.15$ & $8.43 \pm 2.64$ & $13.33 \pm 8.50$ & $16.00 \pm 8.49$ & 2.190 & 0.147 \\
\hline Thigh $(\mathrm{mm})$ & $11.33 \pm 2.52$ & $13.00 \pm 4.55$ & $17.00 \pm 3.00$ & $18.50 \pm 7.78$ & 1.623 & 0.240 \\
\hline $\operatorname{Calf}(\mathrm{mm})$ & $9.00 \pm 3.60$ & $7.57 \pm 1.51$ & $10.67 \pm 4.73$ & $11.50 \pm 4.95$ & 1.183 & 0.361 \\
\hline
\end{tabular}

Notes: W: Wing, B: Back court player, P: Pivot, GK: Goalkeeper; $*$ p $\leq 0.05$

Furthermore significant differences were found between $B$ and $P$ in thigh girth $(\mathrm{p}=0.025)$, chest girth $(p=0.036)$, forearm length $(0.043)$ and metric index $(p=0.011)$. We registered longer forearm in B than P. According to our data GK have significantly greater biceps girth $(p=0.053)$ and ankle girth $(p=0.04)$ than $W$, longer forearm $(p=0.04)$ and biceps girth $(p=0.049)$ than $B$.

After somatotyping (Table 1) W are classified as meso-ectomorphic (2-3-4), B as endoectomorphic (3-2-5), P are mesomorphic (4-5-3) and GK are endo-mesomorphic (4-7-2). Players have well developed bone structure and musculature according to their PLX, P having the biggest (Table 1).

\section{Pulmonary functions in rest}

There were no statistically significant differences between positions in pulmonary functions tested with spirometer. The mean FVC of handball players was $4.71 \pm 0.691$. Each parameter was compared to the reference data of their age-groups. Based on these data FVC of players does not differ significantly from the average adult man. Players have a normal FEV1, mean value: $4.15 \pm 0.50 \mathrm{l} / \mathrm{s}$ and PEF, mean value: $7.83 \pm 1.91 \mathrm{l} / \mathrm{s}$. Tiffeneau-index of subjects is over $80 \%$ due to the quick expiratory functions, which is essential for good performance. FET was $2.26 \pm 0.92 \mathrm{~s}$.

\section{Cardiopulmonary functions on exercise treadmill test}

Results of the spirometry

$\mathrm{RelVO}_{2}$ max was highest of W $(73.93 \pm 9.41 \mathrm{ml} / \mathrm{kg} / \mathrm{min})$ and the lowest of GK $(60.65 \pm 7.99$ $\mathrm{ml} / \mathrm{kg} / \mathrm{min}$ ), but significant differences were not found (Figure 1). 


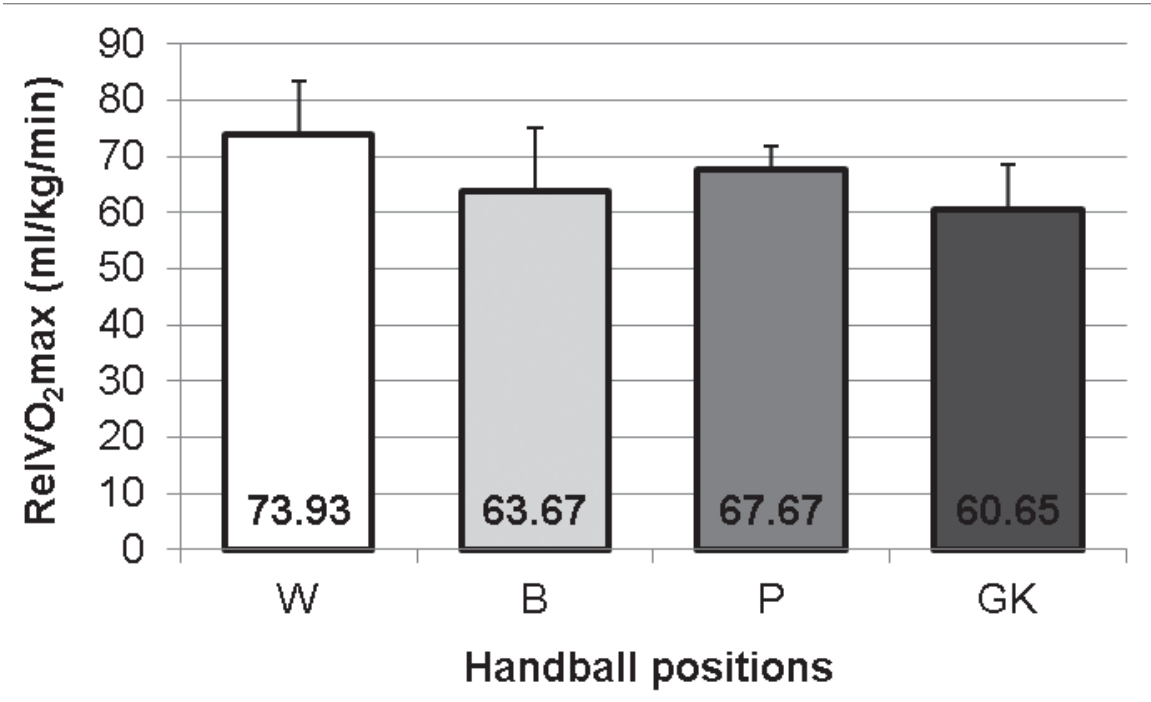

Notes: W: Wing, B: Back court player, P: Pivot, GK: Goalkeeper

Figure 1. Registered mean values of maximal oxygen uptake $\left(\mathrm{relVO}_{2} \mathrm{max}\right)$ in spiroergometric measurement by positions

The mean VT of P was $2.82 \pm 0.151$, which is significantly higher than values of GK $(\mathrm{p}=0.006) /$ Figure $2 /$.

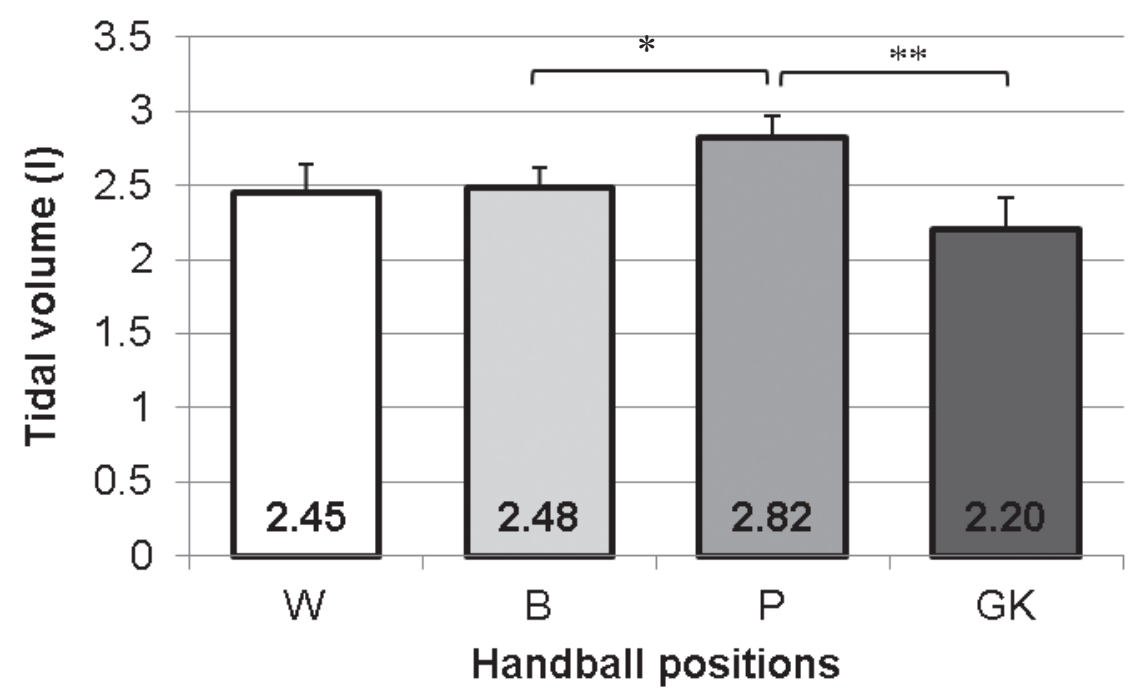

Notes: W: Wing, B: Back court player, P: Pivot, GK: Goalkeeper; ${ }^{*} \mathrm{p} \leq 0.05 ;{ }^{* *} \mathrm{p} \leq 0.01$

Figure 2. The recorded mean maximum tidal volume (VT) of handball players

In the treadmill test we found statistically significant differences in VE at the stage 5 (8.0 $\mathrm{km} / \mathrm{h}, 18 \%$ gradient $)$, stage $6(8.8 \mathrm{~km} / \mathrm{h}, 20 \%$ gradient $)$ and stage $7(9.6 \mathrm{~km} / \mathrm{h}, 22 \%$ gradient $)$ between positions (Figure 3). Ventilatory breakpoint occurred generally at stage $4(6.7 \mathrm{~km} / \mathrm{h}, 16 \%$ gradient) except GK with breakpoint appearing at stage $3(5.4 \mathrm{~km} / \mathrm{h}, 14 \%$ gradient $)$. 


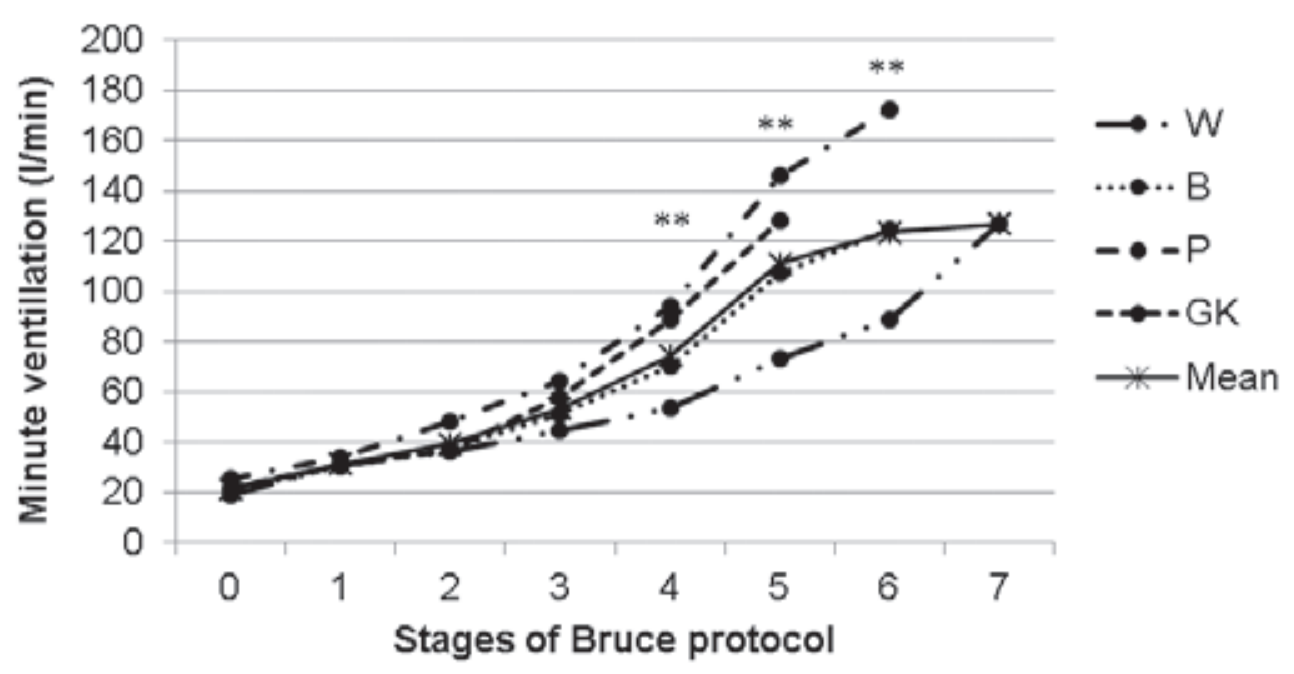

Notes: W: Wing, B: Back court player, P: Pivot, GK: Goalkeeper; ** $\mathrm{p} \leq 0.01$

Figure 3. Changes of mean minute ventilation (VE) during the treadmill test by playing positions

The $\mathrm{W}$ showed the lowest values of lung minute ventilation during the treadmill test. Therefore the maximal mean volume of minute ventilation of $\mathrm{P}(165.53 \pm 13.60 \mathrm{l} / \mathrm{min})$ is significantly higher than recorded values of $\mathrm{B}(128.09 \pm 12.71 \mathrm{l} / \mathrm{min})$ and $\mathrm{W}(128.77 \pm 18.42 \mathrm{l} / \mathrm{min})$.

Players reached RQ: 1.1 relatively late, the average was at stage $5(8.0 \mathrm{~km} / \mathrm{h}, 18 \%$ gradient $)$. At the end of the test the mean RQ was $1.23 \pm 0.09$.

\section{Evaluation of the cardiovascular parameters}

The lowest mean RHR was recorded in W $(87.67 \pm 2.52 \mathrm{bpm})$. During the treadmill test the mean HRmax was $176.33 \pm 7.94 \mathrm{bpm}$ all the athletes (Figure 4). Significant differences were not seen between positions, but the highest HRmax of W $(176.33 \pm 2.08 \mathrm{bpm})$ was measured and the lowest was of $\mathrm{P}(167.67 \pm 8.02 \mathrm{bpm})$.

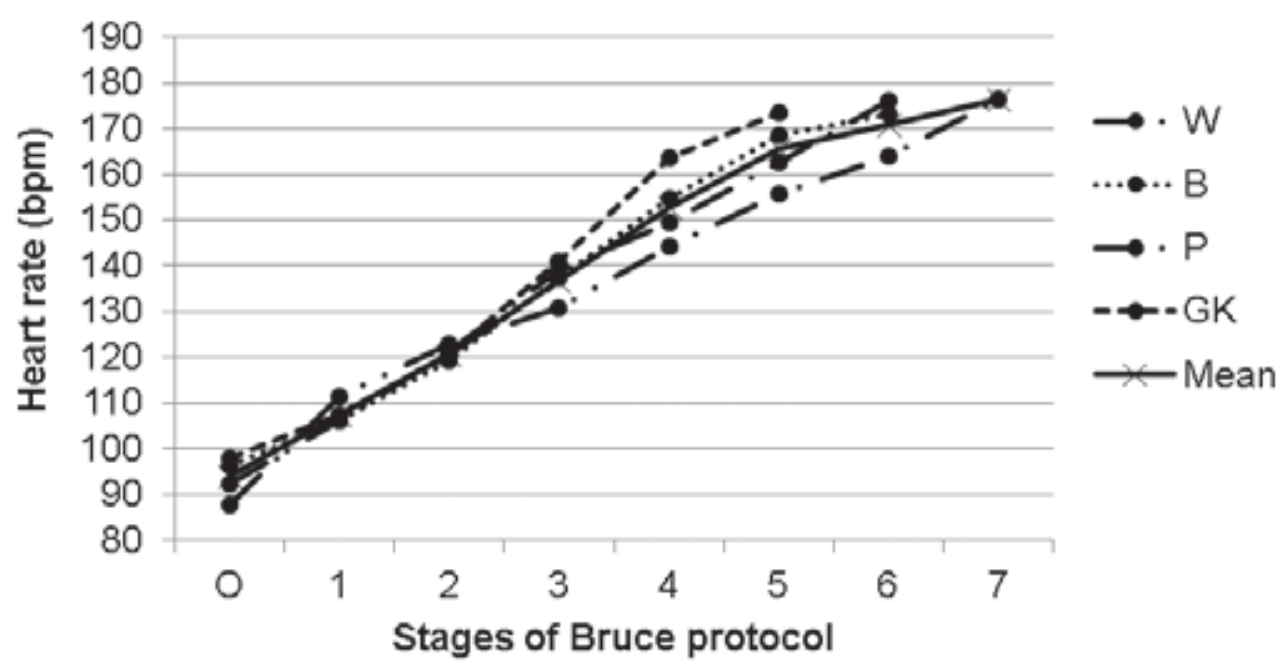

Note: W: Wing, B: Back court player, P: Pivot, GK: Goalkeeper

Figure 4. Changes in mean heart rate (HR) during the stages of vita maxima treadmill test of different playing positions 
As it can be seen in Figure 5, players $\mathrm{P}$ produced superior maximal oxygen pulse $\left(\mathrm{VO}_{2} /\right.$ $\mathrm{HR}=31.47 \pm 1.94 \mathrm{ml} / \mathrm{bpm})$. Players at different positions differed not only in HRmax, but in time spent on treadmill also.

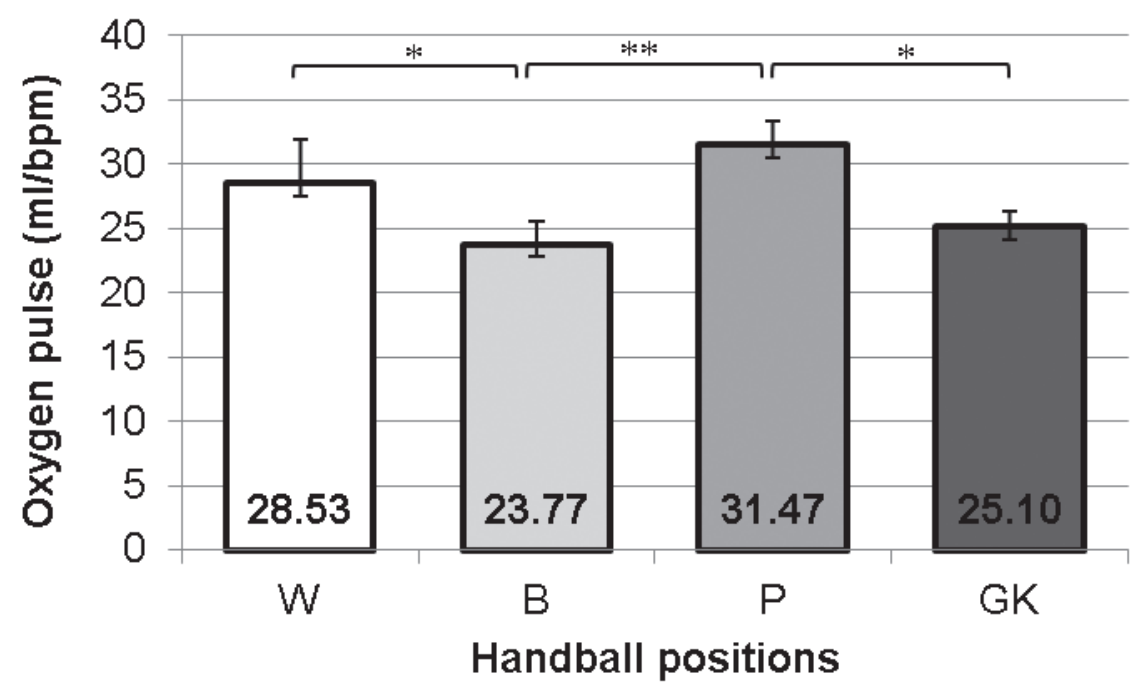

Note: W: Wing, B: Back court player, P: Pivot, GK: Goalkeeper; * $\mathrm{p} \leq 0.05 * * \mathrm{p} \leq 0.01$

Figure 5. Mean values of oxygen pulse $\left(\mathrm{VO}_{2} / \mathrm{HRmax}\right)$ of handball players measured in a vita maxima test

The mean time of treadmill test of $\mathrm{W}$ was the top (20.56 $\pm 0.01 \mathrm{~min})$, which is significantly higher than of $\mathrm{B}(15.55 \pm 2.58 \mathrm{~min}), \mathrm{P}(15.51 \pm 1.45 \mathrm{~min})$ and $\mathrm{GK}(13.80 \pm 0.34 \mathrm{~min})$. Abnormalities were not seen on ECG curves.

\section{Discussion}

The present study investigated possible differences among young male handball players by positions in anthropometric characteristics and cardiopulmonary functions. Differences between positions are visible in many morphological parameters (lean body mass, biceps girth, buttock girth, thigh girth, ankle girth, chest breadth, forearm length, metric index and mesomorphy).

$\mathrm{W}$ presented the best physical condition according to time spent on treadmill and maximal oxygen uptake. As of anthropometric data wings differ the most from other player positions similarly to previous studies (Chaouachi et al., 2009; Sibila et al., 2004; Srhoj et al., 2002). In our research all players are taller than 14 years old Greek male handball players, but they have lower body mass except goalkeepers (Zapartidis, Vareltzis et al., 2009). Earlier researchers registered higher values in thigh girth $(56.16 \mathrm{~cm})$, skinfolds of biceps, triceps and suprailiaca of 14 years old Spanish players (Ibnziaten et al., 2002). The studied Hungarian young handball players have greater body shape, arm length and have almost the same circumference of upper arm, thigh and calf than Flemish Under-16 handball players (Mohamed et al., 2009).

According to these results players in various positions indeed have different anthropometric characteristics as would be expected. The lower lean body mass and lower stature enable $\mathrm{W}$ to create quick departures, while B having greater height generally performs overarm shots above the defenders. $\mathrm{P}$ has robust stature and higher weight because of specific movements in the defense wall. 
However according to Matthys, Fransen et al. (2013) besides body structure differences, young players differ in their maturation (biological age). B are not only significantly bigger in size and better in fitness tests, but also more mature, which might be a disadvantage in an older age group later in adulthood.

Pulmonary functions of players in rest show that mean FVC values of B are the highest. The comparison of pulmonary functions in exercise with other studies is difficult due to use of different treadmill protocols. Mean recorded HRmax of players was $176.33 \pm 2.08 \mathrm{bpm}$ that did not reach the estimated values $(203.95 \mathrm{bpm})$. The recorded HRmax is $86 \%$ of the estimated peak HR, consequently the exercise was submaximal. This may result from the fact that players heart rate during a match over half time is in the aerobic zone: 80-85\% (Cervar, 1998; Loftin et al., 1996). However since players did not reach their expected HRmax the protocol suggested by Hamlin et al. (2012) might be better for testing handball players.

According to the registered $\mathrm{VO}_{2}$ max players have an excellent aerobic capacity. We recorded the highest mean values of oxygen consumption in $\mathrm{W}$ that indeed is necessary for them who generally cover the most distance in a match time (Cuesta, 1991; Sibila et al., 2004). The athletes reach the peak of $\mathrm{VO}_{2} \max$ at this age therefore this is a very sensitive period to develop proper aerobic capacity.

The mean $\mathrm{VO}_{2} / \mathrm{HRmax}$ of players is $26.44 \pm 3.72 \mathrm{ml} / \mathrm{bpm}$. High oxygen uptake is coupled with low heart rate, which refers to an excellent fitness level as well. Based on these data the cardiac function of players is economical.

We found that young handball players presented higher $\mathrm{VO}_{2}$ max and $\mathrm{VO}_{2} / \mathrm{HRmax}$, but less values of HRmax, VE and VT than male handball players on a treadmill test (Vujkov et al., 2010). Greater $\mathrm{VO}_{2}$ max and more efficient breathing are important factors for better performance.

Significant differences were found of young male team handball players between positions of measured anthropometric and cardiopulmonary functions. The differences are the consequences of the characteristics of modern team handball. Besides performance measurements it is important to apply morphological studies for selection of young players already.

Data obtained from complex fitness measurements (anthropometric parameters, HRmax, $\mathrm{VO}_{2} \max$ from exercise treadmill tests) would be useful for professional coaches in selection and talent identification, especially by playing positions. Data also can be applied for planning specific training programs for the different positions.

\section{References}

Bruce, R. A. (1971). Exercise testing of patients with coronary heart disease. Principles and normal standards for evaluation. Annals of Clinical Research, 3(6), 323-332.

Buccheit, M., Lepretre, P. M., Behaegel, A. L., Millet, G. P., Cuvelier, G., \& Ahmaidi, S. (2009). Cardiorespiratory responses during running and sport-specific exercises in handball players. Journal of Science and Medicine in Sport, 12, 399-405.

Carter, J. E. L., Rose, W. D., \& Duquest, W. (1983). Advances in somatotype methodology and analyses. Yearbook of Physical Anthropology, 28, 193-212.

Cervar, L. (1998). La Pallamano Secondo Me. Roma: Coni-Scuola dello sport. 
Chaouachi, A., Brughelli, M., Levin, G., Boudhina, N., Cronin, J., \& Chamari, K. (2009). Anthropometric, physiological and performance characteristics of elite team handball players. Journal of Sport Sciences, 27(2), 151-157.

Conrad, K. (1963). Der Konstitutionstypus. Berlin: Springer.

Cuesta, G. (1991). Balonmano (Team handball). Madrid: Spanish Handball Federation.

Galal El-Din, H., Zapartidis, I., \& Ibrahim, H. (2011). A comparative study between talented young Greek and German handball players in some physical and anthropometric characteristics. Biology of Sport, 28, 245-248.

Gorostiaga, E. M., Granados, C., Ibanez, J., \& Izquierdo, M. (2005). Differences in physical fitness and throwing velocity among elite and amateur male handball players. International Journal of Sports Medicine, 26(3), 225-232.

Hasan, A. A. A., Rahaman, J. A., Cable, N. T., \& Reilly, T. (2007). Anthropometric profile of elite male handball players in Asia. Biology of Sport, 24(1), 3-12.

Hamlin, M. J., Draper, N., Blackwell, G., Shearman, J. P., Nicholas, E., \& Kimber N. E. (2012). Determination of maximal oxygen uptake using the Bruce or a Novel Athlete-Led Protocol in a mixed population. Journal of Human Kinetics, 31, 97-104.

Ibnziaten, A., Poblador, M. S., Leiva, A., Gómez, J. R., Viana, B., Nogueras, F. G., \& Lancho, J. L. (2002). Body composition in 10 to 14-year-old handball players. European Journal of Anatomy, 6(3), 153-160.

Loftin, M., Anderson, P., Lytton, L., Pittman, P., \& Warren, B. (1996). Heart rate response during handball singles match-play and selected physical fitness components of experienced male handball players. Journal of Sports Medicine and Physical Fitness, 36(2), 95-99.

Luszczyk, M., Ziemann, E., Grzywacz, T., Laskowski, R., \& Szczęsna-Kaczmarek, A. (2010). Cardiorespiratory responses to submaximal exercise in 16-18-year-old trained and untrained boys. Baltic Journal of Health and Physical Activity, 2(1), 30-35.

Marques, M. C., Tillaar, R., Vescovi, J. D., \& González-Badillo, J. J. (2007). Relationship between throwing velocity, muscle power and bar velocity during bench press in elite handball players. International Journal of Sports Physiology and Performance, 2, 414-422.

Massuca, L., \& Fragoso, I. (2011). Study of Portuguese handball players of different playing status. A morphological and biosocial perspective. Biology of Sport, 28, 37-44.

Matthys. S. P. J., Vaeyens, R., Vandendriessche, J., Vandorpe, B., Pion, J., Coutts, A. J., . . . \& Philippaerts, R. M. (2011). A multidisciplinary identification model for youth handball. European Journal of Sport Science, 11(5), 355-363.

Matthys, S. P. J., Fransen, J., Vaeyens, R., Lenoir, M., \& Philippaerts, R. M. (2013). Differences in biological maturation anthropometry and physical performance between playing positions in youth team handball. Journal of Sports Sciences, 31, 1344-1352.

Matthys, S. P. J., Vaeyens, R., Fransen, J., Deprez, D., Pion, J., Vandendriessche, J., . . \& Philippaerts, R. (2013). A longitudinal study of multidimensional performance characteristics related to physical capacities in youth handball. Journal of Sports Sciences, 31(3), 325-334.

Mohamed, H., Vaeyens, R., Matthys, S., Multael, M., Lefevre, J., Lenoir, M., \& Philppaerts, R. (2009). Anthropometric and performance measures for the development of a talent detection and identification model in youth handball. Journal of Sports Sciences, 27(3), 257-266. 
Rivilla-Garcia, J., Navarro, F., Grande, I., Ignatova, A., \& Sampedro, J. (2010). Differences in throwing capacity between senior and U18 men handball players. Serbian Journal of Sport Sciences, 4(4), 145-151.

Sibila, M., Vuleta, D., \& Pori, P. (2004). Position-related differences in volume and intensity of large-scale cyclic movements of male players in handball. Kinesiology, 36(1), 58-68.

Skoufas, D., Kotzamanidis, C., Hatzikotoylas, K., Bebetsos, G., \& Patikas, D. (2003). The relationship between the anthropometric variables and the throwing performance in handball. Journal of Human Movement Studies, 45, 469-484.

Sporis, G., Vuleta, D., Vuleta Jr., D., \& Milanović, D. (2010). Fitness profiling in handball: physical and physiological characteristics of elite players. Collegium Antropologicum, 34(3), 10091014.

Srhoj, V., Marinovic, M., \& Rogulj, N. (2002). Position specific morphological characteristics of top-level male handball players. Collegium Antropologicum, 26(1), 219-227.

Vujkov, S., Đukic, M., \& Drid, P. (2010). Aerobic capacity of handball players with hearing impairment. Biomedical Human Kinetics, 2, 58-61.

Zapartidis, I., Toganidis, T., Vareltzis, I., Christodoulidis, T., Kororos, P., \& Skoufas, D. (2009). Profile of young female handball players by playing position. Serbian Journal of Sports Sciences, 3(1-4), 53-60.

Zapartidis, I., Vareltzis, I., Gouvali, M., \& Kororos, P. (2009). Physical fitness and anthropometric characteristics in different levels of young team handball players. The Open Sports Sciences Journal, 2, 22-28.

Zapartidis, I., Kororos, P., Christodoulidis, T., Skoufas, D., \& Bayios, I. (2011). Profile of young handball players by playing position and determinants of ball throwing velocity. Journal of Human Kinetics, 27, 17-30.

Ziv, G., \& Lidor, R. (2009). Physical characteristics, physiological attributes, and on-court performances of male handball players. European Journal of Sport Science, 9, 375-386. 